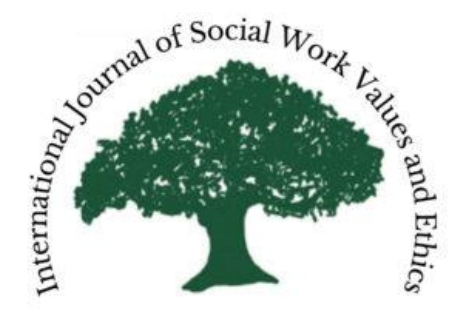

International Journal of Social Work Values and Ethics

Volume 19, Number 1 (2022)

ISSN: 2790-6345

DOl: 10.55521/10-019-100

www.jswve.org 


\section{Editorial: Exposing White Privilege by Two White Guys}

DOl: 10.55521/10-019-101

Stephen M. Marson, Ph.D., Editor and Paul Dovyak, MSW, LISW-S

International Journal of Social Work Values and Ethics • Volume 19(1), Copyright 2022 by IFSW

This text may be freely shared among individuals, but it may not be republished in any medium without express written consent from the authors and advance notification of IFSW.

A South politician preaches to the poor white man

"You got more than the blacks, don't complain

You're better than them, you been born with white skin," they explain

And the Negro's name

Is used, it is plain

Bob Dylan

Only a Pawn in Their Came

This editorial represents our conversations regarding the racial turmoil we followed through the media during the years 2019 to 2021 . We awkwardly reminisced our youth during the turbulent 1960's and concluded that many similarities exist between the social revolutions of the 60's and today. Essentially this editorial is a recapitulation of our conversations. These conversations cycled through reactions of intellectualization, anger, irrationalities, irony, sarcasm, depression and embarrassment about being white. Assembling these fragments of ideas and feelings was a Herculean task. We spent as much time on this seemingly simple editorial as we would on a major research manuscript. Essentially, we have attempted to integrate our affective reactions with our intellect. In assembling these fragments of ideas we believe that we should start with some intellectualization. Thus, we begin with the assumption that to understand the concept of "white 
privilege," it is critical to clarify how it intersects with the concept of "white supremacy."

\section{White Privilege and White Supremacy}

White supremacy is founded on a sociopolitical history of projecting biological determinates for which there is no known genetic basis. Social psychology and psychiatry might further trace through the Nuremberg Trials how societies interact to sustain the dynamics of domination and oppression. In fact, the biological and anthropological evidence suggests that racial superiority simply does NOT exist. Robert Merton would classify white supremacy as a manifest function. Manifestly and unambiguously, the position for white supremacy can be summarized as: "Whites are superior to everyone else [sic] because they dominate." Although there are a number of people who embrace this position, they lack scientific evidence to support their position. In some ways then, white supremacy may be the psychiatric strawman that can be easily knocked over with science principles. Thus, being contrary to the scientific substantiated reality, the existence of feelings of white supremacy becomes an issue for psychiatric intervention - perhaps pharmaceutical or electroshock therapy. White supremacy is a socio-political reality that sustains variant streams of social injustice to allow innumerable types of oppression.

White privilege is sociological (less psychiatric) in nature with an absence of biological and psychological principles. Unlike white supremacy which is clearly manifest, Robert Merton would envision white privilege as latent and deeply embedded within the social structure without conscious acknowledgement. Marxist scholars and feminist researchers would employ the concept "false consciousness" to define white privilege. Thus, white privilege is deeply embedded within our social infrastructure. White privilege is insidious. Thus, a white or Black person can truly believe that white supremacy is abhorrent, but simultaneously embrace white privilege without conscious awareness. 
White privilege is better understood as an evolved rationalization for white supremacy. After generations of passive sociological denial, our country may be birthing an unwanted pregnancy. It is a Constitutional certainty that white supremacy was a founding principle of our country. Gerson (2021) describes the hesitancy of her colleagues to more fully embrace exposure and reminder of the stain of the Supreme Court Dred Scott decision (1857). The tortuous logic of our white AND male 'forefathers' to so fundamentally argue a 'three-fifths' human clause shames any revisionist publisher of our Constitution. Three Amendments were required to correct this imperfect union.

If the reader teaches race relations or social justice, Robert Merton's sociological concepts of manifest and latent and the Marxian concept of false consciousness are prerequisite concepts necessary to have an in-depth understanding of white privilege. These concepts lead us and our students to unambiguously acknowledge that white privilege is far more of a danger to society than white supremacy.

In examining white privilege and white supremacy, we concluded that white privilege is much more of a micro concept while white supremacy is macro. Based on our conversations, we developed a typology that may be helpful for teaching instructional purposes:

\begin{tabular}{l|l|l|}
\multicolumn{1}{c|}{ Characteristics } & \multicolumn{1}{c|}{ White Privilege } & \multicolumn{1}{c|}{ White Supremacy } \\
\hline \multirow{2}{*}{$\begin{array}{l}\text { Locus of Control } \\
\text { Origin }\end{array}$} & External / Passive/Aggressive & Internal / Aggressive \\
\cline { 2 - 3 } $\begin{array}{l}\text { Group Influence } \\
\text { Feelings }\end{array}$ & Sociological & Psychiatric \\
\cline { 2 - 3 } $\begin{array}{l}\text { Intervention } \\
\text { Best Literature } \\
\text { Population Proportion }\end{array}$ & Subconscious & Grandiosity \\
\cline { 2 - 3 } & Collective Unconscious & Collective Conscious \\
\cline { 2 - 3 } & Naivete & Agitation \\
\cline { 2 - 3 } & Policy \& Laws & Deprogramming \\
\cline { 2 - 3 } & Sociological Abstracts & Psychological Abstracts \\
\cline { 2 - 3 } & Majority & Loud Minority \\
\hline
\end{tabular}

Table 1: Typology of White Privilege and White Supremacy 


\section{The Emergence of White Privilege}

What is the derivation of "white privilege"? White privilege is an extremely elusive concept. According to Smith, Crosthwaite and Clark (2014) white privilege originally emerged within Critical Race Theory (CRT) in conducting research on the courts' sentencing practices. Within the jurisprudence literature, the CRT position states that race-based preferences and biases are embedded in established law and policy. In terms of criminal justice, social workers are well-aware of a pattern of harsher sentences for the identical crime among Blacks when compared to convicted whites. In addition to harsher sentences, Blacks are more likely to be convicted whereas whites are less likely. The Criminal Justice System is the origin and the explanation of how the concept of white privilege came into existence.

\section{Two Examples: Example 1}

A further extension of white privilege to male privilege was displayed in the judiciary in the nomination and confirmation of Brett Kavanaugh to the United States Supreme Court. Kavanaugh was accused of the attempted rape of a 15-year-old girl while he was 17 . During the Judiciary Committee hearing, the allegations boiled down to "he said, she said." The vote to confirm Kavanaugh fell into the hands of female Senator Susan Collins.

As stated within the definition, white privilege is embedded within our social structure in such a profound manner, it goes unnoticed by those who are hurt by it but are compelled to endorse it. Such a social environment is fertile soil for conflict theory's concept of "false consciousness." In fact, the concept of false consciousness is the foundation to enable white privilege to continue and thrive. To help her decide to endorse Kavanaugh, Senator Collins requested to have three meetings in which she interrogated him. On the surface this sounds reasonable. However, from the perspective of someone assessing the situation from a white privilege perspective, there is a problem here. Collins made no effort to meet with Christine Blasey Ford - the alleged victim. It is true that the standard protocol within the Senate bears 
no necessity for a senator to request a private meeting with the opposition. The most notable aspect of the normal established protocol within the Senate is that it fits, like hand in glove, the definition of white privilege within the history of the judiciary. As stated earlier, preferences and biases are embedded in established law and policy. The concept of failing to interview Ford is normal. It is fundamentally dismissive. In terms of white privilege, legal norms must be challenged.

In fact, failure to consider interviewing Ford demonstrated the existence of false consciousness. We see that Collins acquiescing to white male superiority by denying Ford an equal opportunity to explain in her own words - unfettered by prying eyes - equal to the Kavanaugh interviews. We see a vision of male superiority and second-class citizenship for women because Ford and Kavanaugh were not treated equally. The rationale for excluding a Ford interview exists and is quite believable within our political framework. However, these political rationales are also the latent characteristics of white privilege. Among Republicans, there were cries that took the position that the rejection of Kavanaugh would be grossly unfair. We cannot deny a job to white man who has a lifetime of privilege. The pertinent question: Is it impossible to find a conservative white male judge that does not have a rape allegation? This question reinforces the notion of white privilege within a white male dominated judiciary. The key characteristic is: No one questioned the process.

\section{Two Examples: Example 2}

A second example of white privilege within jurisprudence is found in Judge Persky's disposition of Brock Turner's three felony convictions for the rape of Chanel Miller. Turner was convicted of sexual assault for which the maximum sentence was 14 years. The female prosecutor recommended six years. Judge Aaron Persky, a white male judge, ordered a six-month sentence for which Turner served three months - one month for each felony conviction. 
Because the sentence was ridiculously light, Judge Persky felt compelled to offer six justifications to form the basis of this extraordinary light sentence (for all six see: www.theguardian.com/us-news/2016/jun/14/stanford-sexual-assault-read-sentence-judge-aaron-persky). Most of his considerations were founded on the amount of trauma in which Turner, the convicted rapist, would be subjected if he received a harsher imprisonment. Judge Persky's last rationale is quoted:

"... adverse collateral consequences on the defendant's life resulting from the felony conviction. And those are severe. And they're severe in a couple of ways: One, with respect to the Penal Code section 290 registration that he'll be subject to for life; and, secondly, with respect to the media attention that's been given to the case, it has not only impacted the victim in this case, but also Mr. Turner. Where, in certain cases, there is no publicity, then the collateral consequence on those on the defendant's life can be minimized."

Although judges must be given latitude in sentencing, Judge Persky's final disposition of the Turner conviction received universal condemnation. In practical terms, a six-year prison sentence would mean three years in prison. Actually, a light sentence from the judge would have threeyears and in practical terms, he would serve a year and a half. Regardless of how one cuts the cake, the Turner rape case is a classic example of white privilege - a white judge disposes a ridiculously mild sentence to an upper middle-class white boy. Although Judge Persky had the support of the white male dominated stakeholders in California, great international protests emerged, and the people of California removed Persky from his judgeship. We can refer to the people's reaction to Judge Persky's sentencing as a "backlash."

\section{White Privilege in Everyday Life}

Employing white privilege outside the jurisprudence arena is stretching CRT to its limits of coherency. However, the popular press has done this. For example, Smith, Crosthwaite and Clark (2014) stress that two types of white privilege exist within our social structure. They envision white privilege as a 
twofold triumph. First, white males face fewer negative consequences for violating social norms. Second, white males are afforded social opportunities that are limited and/or even denied to women and people of color. As one can easily observe, on the popular front, YouTube offers a massive trove of white social advantages:

https://www.youtube.com/watch?v=vksE]R9EPQ8\&bpctr=1608648415

https://www.youtube.com/watch?v=q2h4CVt1f2l

https://www.youtube.com/watch?v=1PaZzKkGhtc\&t=1s

https://www.youtube.com/watch?v=MktXtg]BiuE

https://www.youtube.com/watch?v=KqARrnQdcQM

https://www.youtube.com/watch?v=hdNKpnXnmGE

https://www.youtube.com/watch?v=N6xnoODRIBQ

https://www.youtube.com/watch?v=Nx5DxpNxDNY\&t=2s

https://www.youtube.com/watch?v=j1mq1P8V_8s

https://www.youtube.com/watch?v=EZPJZkTmBi4

https://www.youtube.com/watch?v=IPubUIKLzsM\&t=14S

https://www.youtube.com/watch?v=fbPzsREhrUA

https://www.youtube.com/watch?v=jEAHBl7OWBY\&t=1s

https://www.youtube.com/watch?v=HtdLalpLQ3M

https://www.youtube.com/watch?v=iQbq40WqQuc

https://www.youtube.com/watch?v=ODhNRyj]sl8\&t=53s

https://www.youtube.com/watch?v=m7qk-5CzoPI

https://www.youtube.com/watch?v=DaBAbxZGokY

https://www.youtube.com/watch?v=I-d8XtujC98

https://www.youtube.com/watch?v=LgaU1hoQiLo

https://www.youtube.com/watch?v=jNBeF2ByPu8

https://www.youtube.com/watch?v=cSzNBo-1R8A

https://www.youtube.com/watch?v=817n6l5mrkM

https://www.youtube.com/watch?v=KTAG50fqYlk

https://www.youtube.com/watch?v=43gm3ClePno 
These short videos that illustrate white privilege can be employed in the classroom to illuminate the concept of white privilege to students.

\section{Personal Anecdote: Example 1}

After attending a conference on white privilege in Canada, Steve found himself to be distressed. Among the participants, Steve got the distinct impression, as a white man, he was to be blamed for social injustice. He had two close friends with whom he attended the conference. One was a lesbian while the other was a Black male. With great finesse, they both gently told Steve that he didn't understand white privilege. They travelled together on the plane ride from Canada to the US where they would connect to different flights homeward bound.

When they arrived at the airport to transfer planes, all three were hungry and decided to eat at a fast-food restaurant. Upon arriving, the restaurant was total chaos. There were no lines and people were mulling around in a state of polite confusion. No one was getting their food! Without being prompted, Steve went to the counter and told everyone to form a line. Steve asked who the first person was to arrive then told her to get in line first then the second arrival and so on. In less than a minute Steve got everyone organized. When Steve returned to his two friends, they both glared at him and almost simultaneously said, "that's white privilege." Steve responded by stressing that they would have eventually done the same thing. Both responded with an emphatic NO. The social concept of white privilege finally clicked in his head and he immediately apologized for his reflex action of taking over. Once again, both responded with a "NO! They want him that way! otherwise they would have never had a chance to eat." This illustrates and shows us that white privilege can be a double-edged sword. Sometimes white privilege serves a social function. OR perhaps everyone should be entitled to have white privilege. OR white privilege is a normal social function, and everyone is entitled to it. OR, whoever is wearing the persuasive personality trait of the day floats as the leader! 


\section{Personal Anecdote: Example 2}

Another personal example involves an application for a Ph.D. program. Steve received a reply from his application which reported that he was the type of candidate they were seeking. The university had an affirmative action policy. The Ph.D. program was obligated to enrol Puerto Rican applicants during that current fiscal year. When Steve got the rejection, he told this story to his Native American students who cheered at the outcome. They envisioned Steve as a white man of great privilege, and they were glad to witness his defeat. Steve's immediate response was, "I am not upset. I don't need help to get accepted and I know l'll eventually be admitted." His sincerity shocked his students, and silence emerged. If a pin dropped, you could hear it. He didn't tell them that he applied to three schools and was immediately accepted to the other two. We don't know if multiple applications for Ph.D. programs were the norm in the late 70's, but no one guided him to do so. Is that white privilege?

\section{Personal Anecdote: Example 3}

Girard and Steve travel to the gym at 4 AM every morning from their respective homes. It is an uneventful trip for Steve. However, Girard, on at least three occasions, was stopped by the police and searched without cause. During one of these three times, Girard walked from the door of his home to his car. Within these few feet of walking, Girard was stopped by police at gunpoint. Girard was emotionally shaken, but after the harsh police interrogation, he drove to work - late. Steve had been driving to the gym for over two decades (commonly over the speed limit) and has never been stopped by the police or anyone else. Since Girard is Black and Steve is white, the decisions made within the criminal justice system, constitutes white privilege.

Steve cannot be held responsible for the lack of social justice faced by his friend Girard. What can Steve do to address this social injustice? His first thought was to make the situation public by publishing a paper. You're reading it. If you have additional ideas, send them to smarson@nc.rr.com. 


\section{Academic Perspective}

Lui (2017) writes, "white wealthy men use privilege as a means to access and gain power while white men in lower-and working-classes use privilege to build relationships and legitimize inequality" (p. 349). We find this conclusion perplexing. Wealthy people, regardless of their sex and race, have few restrictions to access in gaining more power and wealth. The fact is, people with wealth have social and legal privileges the rest of us do not. If O] Simpson was poor, he would have been found guilty. Technically, this situation is outside of the realm of white privilege. More precisely, it should be labelled wealth privilege.

Heller (2009) seems to be suggesting that white privilege does not exist for working class whites. In the trades such as carpentry, auto mechanics, plumbing etc., a person's skill set (regardless of race or sex) is immediately recognized and rewarded. Historically, gaining admission to the journeyman's or other trade training for women and people of color is associated with executive orders from the U.S. presidency. Within political parties who demand small government, we notice a decrease of women and people of color enrolled in trade programs. Whereas political parties who believe that government can create an even playing field, we have an increase of women and people of color enrolled (Hunte, 2016). Thus, white privilege is governmentally regulated in predictable ways or as Merton would suggest, it is a latent social function.

White men who search for the truth are likely to experience cognitive dissonance. However, when requiring two books to be read, one immediately after the other, students regardless of their race, experience cognitive dissonance and will find the concept of white privilege elusive. The books are:

Connerly, W. (2007). Creating equal: My fight against race preferences. Encounter Books.

Suskind, R. (2005). A hope in the unseen: An American odyssey from the inner city to the ivy league. Broadway Books. 
Both books are powerfully presented and take opposite views - both of which are objectively convincing. However, if the positions are truly opposite, both cannot be true?

\section{Applied White Privilege}

What level of credibility or legitimacy do two white guys have in addressing the topic of white privilege? We must acknowledge that our discussions focusing on white privilege were stirred during the tumultuous late spring of 2020. Thus, our narrative on the topic has persisted as a sidebar to the national drama's perfect storm. Pandemic begets racial strife begets economic shutdown. Our discussions were both an intellectual examination of the scholarly literature peppered with lifetimes of personal reflection. No matter what our conversations or rationales developed, we both experienced a state of awkwardness.

One issue emerged true: White privilege exists and is a product and fuel of our society and social structure. What can two white guys do about it? After reviewing the literature and examining our personal experiences, we see the strategy to overcome white privilege resting within the dialogue of white men confronting other white men. In fact, a most meaningful credibility and legitimacy to challenge white privilege rests in the words of the white men who are bold enough to denounce it. There are simple skirmishes that emerge within daily lives of white men. When white men are passive or silent when confronted with racist remarks, racism is strengthened. Enduringly painful offenses can be found within the posts on Facebook. Following is a typical example of a post found on a white man's Facebook: 


\section{'White Privilege'}

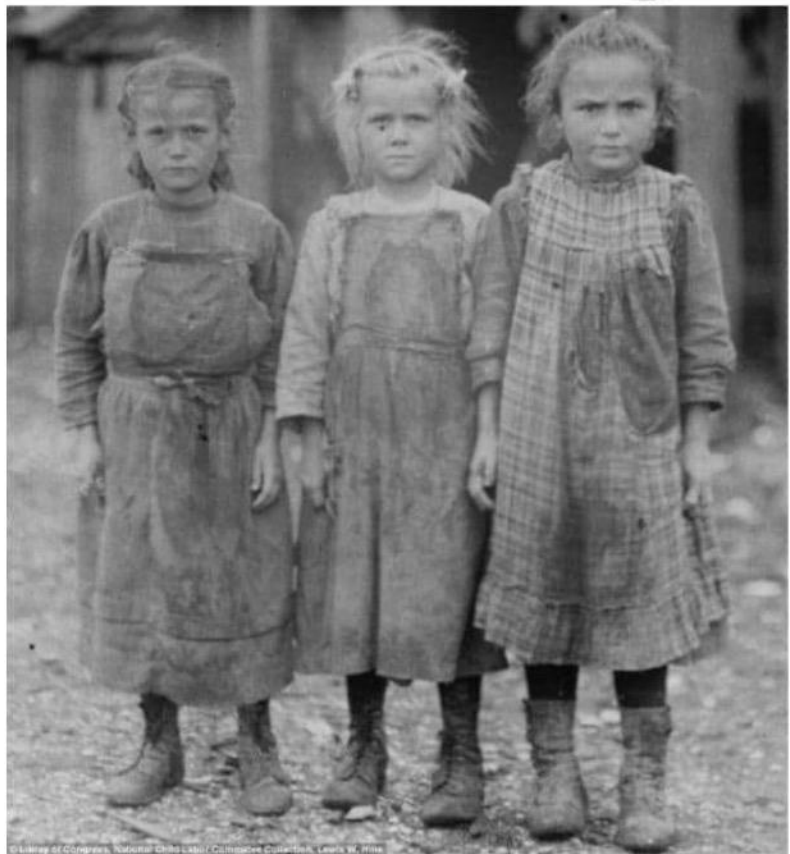

\section{is a Myth Perpetuated by Those Who Hate White People}

Jim Wills

February 20 at 11:05 PM. 0

1 Comment
d3 Like
Comment
Share

Stephen M. Marson

This is absolutely false and not even partly true. The origin of white privilege is found in jurisprudence research during the systematic analysis of sentencing patterns. I actually coauthored a paper on this topic which will be published in the spring of 2022 .

Like - Reply - $8 \mathrm{~h}$

Figure 1: Facebook Post 
Allowing this post to pass without critical comment does nothing but perpetuate white privilege and racism. That is its manifest intent. This post, and others like it, must face an unambiguous protest from white men. Such an objection to racist posts reaches its crescendo when the condemnation comes from another white males. "The only thing necessary for the triumph of evil is for good men to do nothing." Thus, when a white man does nothing in the midst of a racial slur, racism is strengthened and perpetuated. Here, we are approaching the border of unethical professional behavior. The battle of racism is a battle among white men. The question presumes: If a white male social worker fails to respond to racial slurs, that is, doing nothing - is this lack of action unethical?

You are encouraged to send your opinion regarding white privilege to mailto:smarson@nc.rr.com.Your commentary will be published and unedited.

\section{References}

Connerly, W. (2007). Creating equal: My fight against race preferences. Encounter Books.

Gersen, J.S. (2021). The importance of teaching Dred Scott. The New Yorker (online) https://www.newyorker.com/news/our-columnists/theimportance-of-teaching-dred-scott

Heller, ]. (2009). Academic and white working-class perceptions of the economic aspects of white privilege (Order No. AAl1458578). Available from Sociological Abstracts. (60349094; 201023344).

Hunte, R. (2016). Black women and race and gender tensions in the trades. Peace Review, 28(4), 436-443.

Liu, W. M. (2017). White male power and privilege: The relationship between White supremacy and social class. Journal of Counseling Psychology, 64(4), 349-358.

Miller, C. (2020). Know my name: A memoir. Penguin. 
Smith, A., Crosthwaite, J., \& Clark, C. (2014). White privilege. In S. Thompson (Ed.), Encyclopedia of diversity and social justice. Rowman \& Littlefield Publishers.

Suskind, R. (005). A hope in the unseen: An American odyssey from the inner city to the ivy league. Broadway Books. 